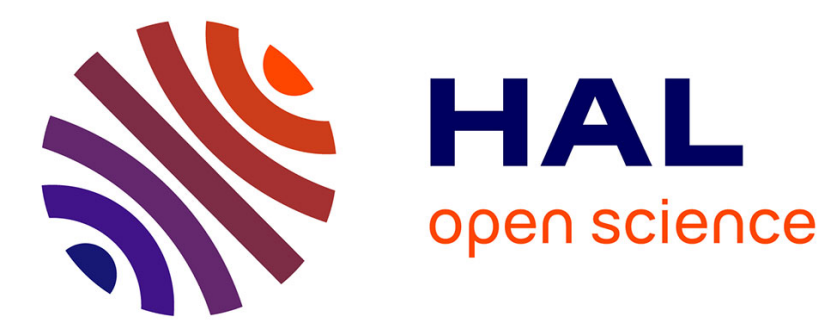

\title{
Mapping Radial, Tangential and Longitudinal Shrinkages and Relation to Tension Wood in Discs of the Tropical Tree Symphonia globulifera
} Bruno Clair, Gaëlle Jaouen, Jacques Beauchêne, Meriem Fournier

\section{To cite this version:}

Bruno Clair, Gaëlle Jaouen, Jacques Beauchêne, Meriem Fournier. Mapping Radial, Tangential and Longitudinal Shrinkages and Relation to Tension Wood in Discs of the Tropical Tree Symphonia globulifera. Holzforschung, 2003, 57 (6), pp.665-671. 10.1515/HF.2003.100 . hal-00004531

\section{HAL Id: hal-00004531 https://hal.science/hal-00004531}

Submitted on 22 Mar 2005

HAL is a multi-disciplinary open access archive for the deposit and dissemination of scientific research documents, whether they are published or not. The documents may come from teaching and research institutions in France or abroad, or from public or private research centers.
L'archive ouverte pluridisciplinaire HAL, est destinée au dépôt et à la diffusion de documents scientifiques de niveau recherche, publiés ou non, émanant des établissements d'enseignement et de recherche français ou étrangers, des laboratoires publics ou privés. 


\title{
Mapping Radial, Tangential and Longitudinal Shrinkages and Relation to Tension Wood in Discs of the Tropical Tree Symphonia globulifera
}

\author{
By Bruno Clair, Gaëlle Jaouen, Jacques Beauchêne and Meriem Fournier \\ UMR « Ecologie des forêts de Guyane » CIRAD ENGREF INRA, Kourou, Guyane française, France
}

Published in Holzforschung 57 (2003) 665-671

\begin{abstract}
Summary
A method for measuring shrinkage resulting from drying in the three anisotropic directions is developed and tested. Measurements are performed on sawn discs, a technique which simplifies preparation and enables large numbers of measurements. Shrinkage values can be represented as a map of the disc surface; the results indicate that comparisons between shrinkage distribution and tension wood distribution on the discs show a clear relationship and can be measured with relatively high accuracy in reference to the "shrinkage map". In the long term, this method could be useful in the timber industry as a means for choosing the direction in which logs are cut depending on their type of wood composition.
\end{abstract}

Keywords

Drying shrinkage

Tension wood

Symphonia globulifera L.f.

\section{Introduction}

Angiosperms are able to maintain a vertical orientation in the main trunks or "predetermined" angles for branches by generating high tension strains on the upper face of the trunk or branches (Wardrop 1964). This type of mechanical state is accompanied by important changes in the structure of the wood cells (Onaka 1949). The resulting wood is called tension wood, in contrast to "normal wood". The behaviour of tension wood is often different from the normal wood behaviour, notably during drying.

Wood always has a higher moisture content in living trees than in cut timber and the cells walls are saturated. In cut timber, the moisture content reaches an equilibrium depending on the air temperature and humidity, from $12 \%$ in temperate areas to $21 \%$ in tropical areas (Langbour and Pinta 2001). During the transition from the saturated state to the equilibrium state, a strongly anisotropic shrinkage can occur in wood; this shrinkage is defined, for a given direction and a given moisture content, by the equation : $1_{0}-1 / 1_{0}$. Where $1_{0}$ is the length in the saturated state and 1 is the length in equilibrium. The total shrinkage is the shrinkage between the saturated and anhydrous state. The order of magnitude of the total shrinkage in "normal" wood is as follows (Skaar 1988) : 3 to $6 \%$ in radial direction (R); 6 to $12 \%$ in tangential direction (T) and 0.05 to $0.3 \%$ in longitudinal direction (L).

In the tropical tree of this study, Symphonia globulifera L.f., the mean total shrinkage is $5.2 \%$ in the radial direction and $11.4 \%$ in the tangential direction (Cirad 1993). In general, these values are much higher in tension wood, in particular in the tangential direction (about twice as great) and the longitudinal direction (up to 10 times greater) (Skaar 1988; Baillères 1994, Washusen and Ilic 2001, Clair et al. 2003). Only few references give values for radial shrinkage in tension wood. The presence of tension wood can therefore induce disparities in shrinkage values for the same piece of wood for a given direction. These differences can produce important distortions of the wood and even splitting, which can render the wood unusable. It is therefore of interest to predict possible distortions of uncut logs so as to modify the direction the wood is cut and thus limit shrinkage effects on wood quality.

This study develops a method for measuring shrinkage, which can be used directly on entire wood discs cut from logs. Shrinkage is measured in the three principal planes, radial, tangential and longitudinal. This method has also been developed for researchers interested in wood quality, who want to perform measurements on large numbers of samples. The method has industrial applications for optimisation of sawing and quality control.

\section{Materials and Methods}

This study is based on samples of Symphonia globulifera L.f. from trees located in a forest area in the coastal savannah, of the Sinnamary municipality, in French Guyana. The species is found in central and south tropical America, as well as tropical Africa. It is known as "Manil marecage" in French Guyana, "Buckwax tree" in Guyana and Surinam, "Anani”" or "Mani" in Brazil, and the "Paletuvier jaune" in the West Indies. It is a commercial wood and "Mani" is the international trade name used in joinery (Cirad 1993, Gérard et al. 1996). Kiln drying must be handled slowly because there are relatively high risks of distortion and checking, as found in many other commercial species of Clusiaceae used in this area (e.g. Platonia insignis Mart., Moronobea coccinea Aublet or calophyllum lucidum Benth.). 


\section{B. Clair et al. : Mapping Shrinkages and Relation to Tension Wood in Discs}

The sampled tree was selected on account of a high degree of inclination and bending indicating a high probablilty of the development of tension wood.

Growth stresses are estimated (see section growth stress estimation) all around the trunk and at six different heights, from $0.70 \mathrm{~m}$ to $5.60 \mathrm{~m}$. Two discs, representing entire transactions of the trunk, $50 \mathrm{~mm}$ thick, were taken above each measured circumference. A sawing guide allowed us to obtain parallel surfaces for the discs which were cut with a electric band saw. The final surface was prepared with a planing machine. During drying, it is expected that a lot of splits will appear along the radius owing to the fact that the tangential shrinkage is twice the radial shrinkage. To avoid a random distribution of the splits, each disc was cut vertically with a saw and along a single radius from the bark to the core (here above called "radial" saw mark); these cuts were made in the area believed to have the strongest shrinkage and were thus intended to compensate for excessive shrinkage anisotropy (Fig. 2).

For each disc pair, one (main disc) was used for shrinkage measurements and the other (twin disc) for mapping tension wood via a staining procedure. The twin disc is also used to determine the influence of the position of the radial saw mark. For comparison, $20 \mathrm{~mm}$ cubes were taken from the twin disc to measure radial and tangential shrinkage according to a more conventional protocol (micrometric sensor).

\section{Growth stress estimation}

Growth stresses along the grain were estimated on the tree by the "single hole" method (developed by Cirad, formerly CTFT), described by Fournier et al. (1994) and Clair et al. (2003). The growth stress indicator (GSI) is the measure in microns of the gap between two spikes (initially placed $45 \mathrm{~mm}$ apart along the grain) after cutting a hole (20 mm diameter) at the mid point between each spike. The space enlarges when the wood is under tension (= tension wood) and decreases when the wood is under compression (= compression wood). A ring of 8 measurements (one measurement every $45^{\circ}$ ) was carried out at six heights along the trunk (from 0.7 to $5.6 \mathrm{~m}$ ).

\section{Tension wood mapping}

A solution of zinc chloro-iodide was applied to the lower face of each twin disc (protocol described by Grzeskowiak et al. 1996). This stains areas of tension wood dark brown without colouring normal wood (Fig. 1). The discs were then scanned and the limits of the tension wood were marked manually using image software. The image was then inverted so as to correspond to the upper face of the disc dedicated to the shrinkage measure.

Unlike the GSI, this coloration only gives qualitative information (presence or absence) concerning tension wood. However, it does show the distribution of tension wood over the entire disc while GSI only gives information concerning the first few centimetres below the surface.

\section{Tangential and radial shrinkage mapping}

An accurate grid was drawn directly on the surface of the main disc and the growth rings were traced every $5 \mathrm{~mm}$ and the radii towards the centre are marked perpendicularly to the growth rings at approximately every $10^{\circ}$. Each intersection between a radius and a growth ring was marked by a reference point (Fig. 2).

Drying was performed in three steps: natural outdoor air-drying until equilibrium (about $23 \%$ moisture content), natural indoor conditioned air-drying until equilibrium (about $15 \%$ moisture content), and final oven drying at $103^{\circ} \mathrm{C}$ until equilibrium (anhydrous state). During drying, the discs were regularly weighed and scanned in 256 grey levels with 1200 ppi resolution on a commercial scanner. For each moisture content, the co-ordinates of each reference point were recorded with an image analysis software (optimas 6.5). A data treatment enabled the calculation of the distance between two neighbouring points on the same radius (radial distance) or on the same growth ring (tangential distance) for each moisture content. The distance between two points for two different moisture contents related to the distance at saturated state gives the radial and tangential shrinkages between these two points. The shrinkages are then represented by a colour or grey level code. Repeatability tests indicated that the positioning of the points on the scanned image is accurate to the nearest 19 $\mu \mathrm{m}$, which corresponds to less than $4 \%$ error on the shrinkage measurements.

Shrinkage is not entirely unconstrained in a solid disc; however it can be stated from a theoretical point of view that the radial saw cut insures unconstrained relative shrinkage between the radial and tangential directions in a perfectly round and homogeneous disc (Guitard 1987). To evaluate this effect, $20 \mathrm{~mm}$ cubes were taken from the twin disc for independent measurements of radial and tangential shrinkage. The cubes were taken from three different areas : tension wood (TW), normal wood (NW) and from intermediate areas between TW and NW referred to here as intermediate wood (IW) (Fig. 3).

The influence of the radial saw mark position can be estimated by comparing values of total shrinkage corresponding to two twin discs on which saw marks have been placed differently (Fig. 4). This comparison shows that the saw mark position does not significantly influence the measured values. However, when the mark is too far from the area with the strongest shrinkage, and distant from the longest radius (in case of non-centred cores), splits can appear and disturb the measurement.

\section{Longitudinal shrinkage mapping}

Longitudinal shrinkage was measured using a micrometric sensor mounted on a frame with a deep swan neck (18 cm). On the squared face of the discs, contacts were made via a round-headed spindle (1 mm in diameter) for each reference point (Fig. 2); this type of contact and measurement therefore allowed re-positioning of the micrometric sensor. The disc thickness measurements at each point were performed for three moisture content states : saturated, after indoor-drying and anhydrous. The shrinkage values were then represented by a colour- or grey-level code. 


\section{B. Clair et al. : Mapping Shrinkages and Relation to Tension Wood in Discs}

Repeatability tests (150 repetitions of the experimental conditions) indicated that these measurements are accurate to the nearest $19 \mu \mathrm{m}$, which corresponds less than $10 \%$ error in the shrinkage measurements. Although this error is significant, we consider that the accuracy of the system is nevertheless informative as differences in longitudinal shrinkage of over a factor 10 are expected between normal wood and tension wood.

\section{Results and Discussion}

\section{GSI and tension wood mapping}

GSI values range from low compression values $(-15 \mu \mathrm{m})$ to very high tension values $(452 \mu \mathrm{m})$. This indicates that the tree has reacted strongly to induce straightening and strong property contrasts in the wood might therefore be expected. The zinc chloro-iodide stain clearly shows the presence of a different wood type in the areas with strong tensile constraints (this has been verified with a Student test $(\mathrm{p}<0.0001)$ applied to the GSI values of the two types of wood NW and TW).

Anatomical observations indicate that, despite the overall stain reaction with the zinc chloro-iodide, the tension wood cells do not show any distinct (blue) gelatinous layer via staining with safranin - Astra blue. This indicates at least one advantage of the chloro-iodide coloration method in detecting wood which is mechanically under tension, but which does not have cells with distinct G-layers like poplar. The main limitation of this method is the difficulty in applying it to darkcoloured woods.

\section{Shrinkage mapping}

Since the main objective of this article is to present a method for the measuring of distortion after drying rather than focussing in detail on the many properties of tension wood, we will not discuss here the potential presence of cell collapse, which might explain some of the high shrinkage values obtained.

Tangential and radial shrinkage

The maps of tangential and radial shrinkage based on different moisture contents indicate the degree of shrinkage for each studied segment (Fig. 5). These maps allow visualisation of the shrinkage in relation to the type of wood (NW or TW). This is particularly clear in the case of tangential shrinkage, in which contrasts between NW and TW are greater than for radial shrinkage. It is noticeable that shrinkage measurements in the tangential direction are much more homogeneous than those in the radial direction. Observation of the picture of total shrinkage gives the maximum contrast (Fig. 6). The intermediate areas between TW and NW can be better observed compared to the zinc chloro-iodide coloration which only gives an indication of the presence/absence of tension wood rather than intermediate states (Fig. 5).

The results from the measurements of entire discs are compared with those of the reference cube method. The mean radial and tangential total shrinkage obtained on the segments are compared with the corresponding sampling positions represented by mean values for isolated cubes (fig. 7). Despite lower values of radial shrinkage on the discs, the results are coherent between the two methods. This comparison allows validation of the shrinkage measurement method directly on discs. Confrontation shows a better reliability for the tangential direction.

Note that whatever the direction and the method, sample "c" resembled normal wood or intermediate wood more than tension wood. We interpret this result as stemming from the fact that the zone of wood comprised less tension wood than could be detected via the staining.

\section{Longitudinal shrinkage}

Despite the weak dimensional variations in the axial direction, the shrinkage maps did highlight strong contrasts between normal wood and tension wood (Fig. 6). Until a system for fully automating the reference points can be developed the measurements in this direction are easier to carry out than in the $\mathrm{R}$ and $\mathrm{T}$ directions. However, because of its lower accuracy due to the range of variation of longitudinal shrinkage, it does not actually yield as much information on wood heterogeneity as the measurements in transverse directions.

\section{Conclusion}

This study indicates the feasibility of measuring dimensional variations on discs, in particular, in the tangential direction. We applied the method for measuring shrinkage from drying but it can also be performed for observing hygrothermal recovery (Gril et al. 1993) due to steaming. Compared to the closing method proposed by Jullien and Gril (1996), this method gives finer information on the heterogeneity within the entire section rather than global or mean values for the entire disc.

In terms of characterising tension wood, the disc method has the advantage of being usable on all types of wood, while the zinc chloro-iodide coloration method can not be applied to dark-coloured woods, and apparently does not react on some wood species because of the chemical structure of their tension wood. While coloration only indicates simply presence or absence of tension wood, the shrinkage mapping quantitatively shows a gradient in the transition between normal and tension wood. Finally, the fact that tension wood is being measured in terms of its properties during drying means that the mapping technique is directly related to the technological problems of the user (drying warp, bow, checks etc.). Recent technological advances in the field of image analysis and the increasing performance of digitising devices for general use, means that this approach is reliable, inexpensive and easy to carry out. After complete automation, the method could be used in industrial applications such as quality control of discs cut from logs and then integrating these results for optimising how the log would be cut. 
Within a wider framework of research, this method avoids the time-consuming cutting of parallelepipeds with parallel surfaces and which have to be properly orientated in terms of the radial, tangential and longitudinal planes. This is particularly interesting for wood quality studies. Further advantages of the technique include the fact that specialized timber machine tools are unnecessary and the approach would be more within the practical capabilities of the laboratories of foresters and biologists, in particular for studying small diameter trunks (young trunks, branches, roots ...), which are difficult to saw. For the studies on variability, a great number of measurements can be readily performed.

\title{
Acknowledgements
}

Many thanks are due to Elie Baltus, Fernand Boyer and Soepe Koese from the Cirad, for help in cube shrinking measurements and sample machining. We thank also Sylvie Mouras and Nick Rowe for checking the English and making improvements to the manuscript. This study was performed in the framework of the program "reaction wood" funded by ADEME and the French Ministry of Agriculture.

\section{References}

Baillères, H. 1994. Précontraintes de croissance et propriétés mécano-physiques de clones d'Eucalyptus (Pointe-Noire, Congo) : Hétérogénéités, corrélations et interprétations histologiques, PhD Thesis Université Bordeaux I, 161 pp.

CIRAD 1993. Bois des DOM-TOM. Tome 1 - Guyane. Nogent sur Marne, France.

Clair, B., J. Ruelle and B. Thibaut. 2003. Relationship between growth stresses, mechano-physical properties and proportion of fibre with gelatinous layer in chestnut (Castanea Sativa Mill.). Holzforschung 57 (2), 189-195.

Fournier, M., B. Chanson, B. Thibaut and D. Guitard. 1994. Mesure des déformations résiduelles de croissance à la surface des arbres, en relation avec leur morphologie. Observation sur différentes espèces. Annales des Sciences Forestières 51 (3), 249-266.

Gérard, J., R.B. Miller and B.J.H. Welle. 1996. Major Timber Trees of Guyana. Timber Characteristics and Utilization. Tropenbos Series 15. The Tropenbos Foundation, Wageningen, the Netherlands.

Gril, J., E. Berrada, B. Thibaut and G. Martin. 1993. Recouvrance hygrothermique du bois vert. I. Influence de la température. Cas du jujubier (Ziziphus lotus L. Lam.). Annales des Sciences Forestières 50, 57-70.

Grzeskowiak, V., F. Sassus and M. Fournier. 1996. Coloration macroscopique, Retraits longitudinaux de maturation et de séchage du bois de tension du Peuplier (Populus x euramericana cv. I.214.). Annales des Sciences Forestières 53 (6), 1083-1097.

Guitard, D. 1987. Mécanique du Matériau Bois et Composites. Cépadues Editions, Toulouse, France. 220 pp.

Jullien, D. and J. Gril. 1996. Mesure des déformations bloquées dans un disque de bois vert. Méthode de la fermeture. Annales des Sciences Forestières 53 (5), 955-966.

Langbour, P. and F. Pinta. 2001. Séchage naturel du bois en Guyane. Centre Technique des Bois de Guyane, Cirad-Forêt, Kourou, France. 34 pp.

Onaka, F. 1949. Studies on compression and tension wood. Wood research, Bulletin of the wood research Institute, Kyoto University, Japan 24 (3), 1-88.

Skaar, C. 1988. Wood-Water Relations. In: Springer Series in Wood Science. Eds. T. E. Timell. Springer-Verlag, Berlin Heidelberg. pp. 283.

Wardrop, A.B. 1964. Reaction anatomy of arborescent angiosperms. In: The Formation of Wood in Forest Trees. H. Zimmermann. Academic Press, New York. 405-456.

Washusen, R. and J. Ilic. 2001. Relationship between transverse shrinkage and tension wood from three provenance of Eucalyptus globulus Labill. Holz Roh- Werkstoff 59, 85-93.

\author{
Bruno Clair ${ }^{1)}$ \\ Gaëlle Jaouen \\ Jacques Beauchêne \\ Meriem Fournier \\ UMR "Ecologie des Forêts de Guyane" (EcoFoG) CIRAD ENGREF INRA \\ Campus Agronomique, BP 316 \\ 97379 Kourou, Guyane Française \\ France \\ 1) corresponding author \\ clair@lmgc.univ-montp2.fr
}


B. Clair et al. : Mapping Shrinkages and Relation to Tension Wood in Discs

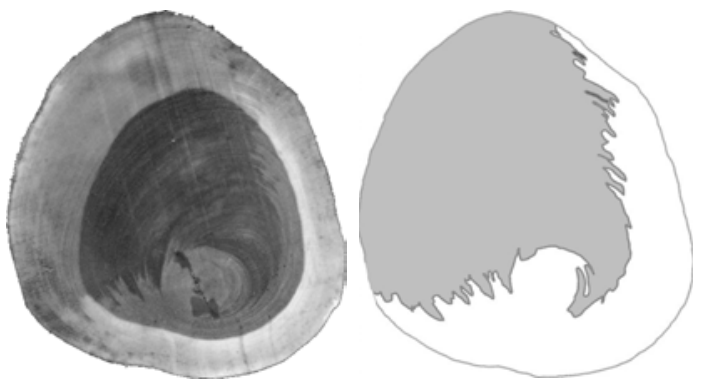

Fig. 1. Macroscopic staining of tension wood on disc with zinc chloro-iodide.

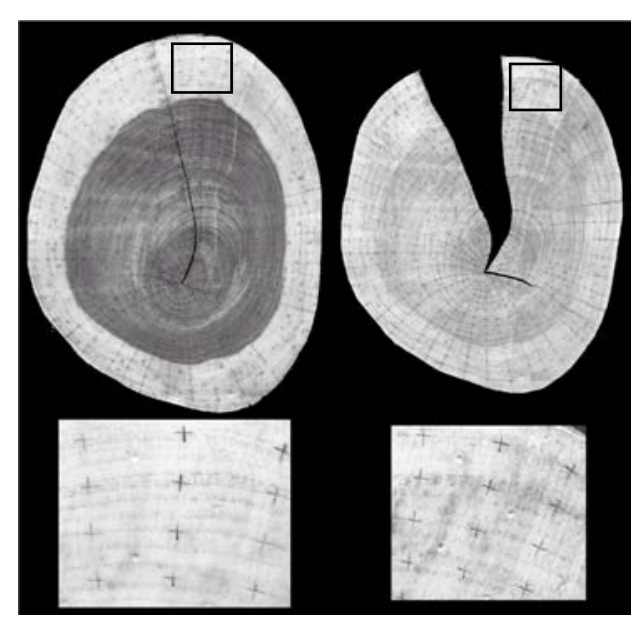

Fig. 2. A scanned disc and a high magnification of reference points used for the radial, tangential and longitudinal shrinkage measurements. Left : saturated state; right : anhydrous state.

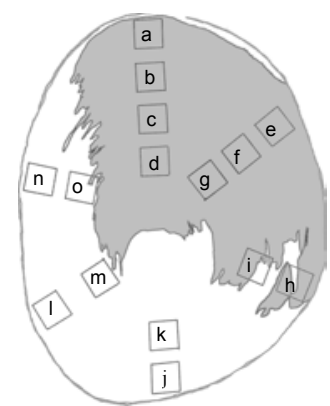

Fig. 3. Positioning of the control cubes on the disc. The grey area corresponds to the zinc chloro-iodide stained area. a,b,c,d,e,f, and g : tension wood; $h$ and i : intermediate wood; j,k,1,m,n and o : opposite wood. 


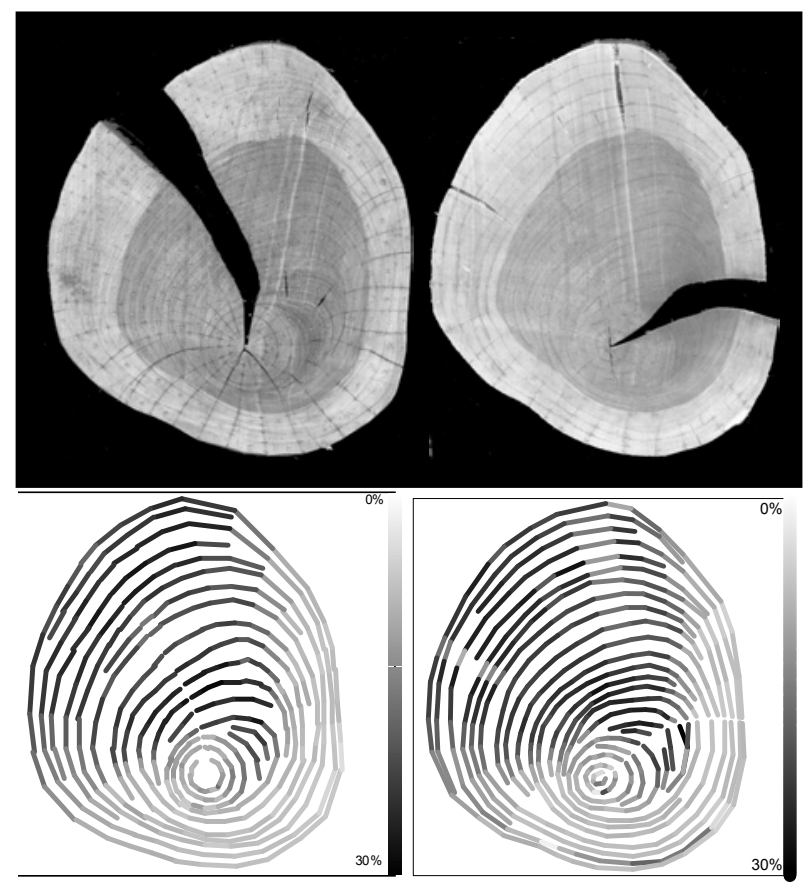

Fig. 4. Effect of the radial saw mark position. Left : test disc with the saw mark on the area of strongest shrinkage. Right : twin disc for comparison. $15 \%$ moisture content state. 
B. Clair et al. : Mapping Shrinkages and Relation to Tension Wood in Discs
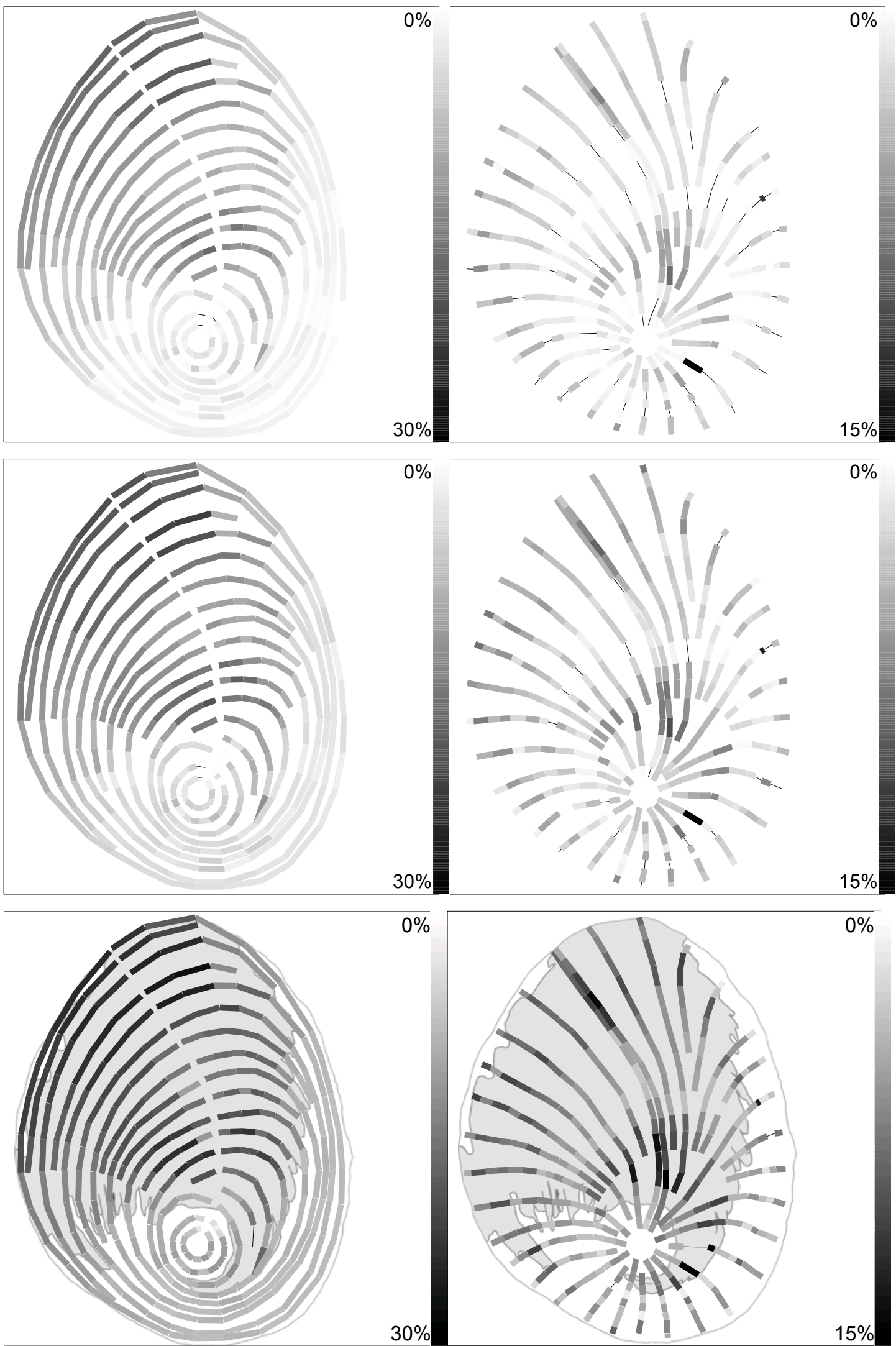

$0 \%$

Fig. 5. Variations in shrinkage on drying. Left : T shrinkage; right : R shrinkage; top : $25 \% \mathrm{MC}$; middle : $17 \% \mathrm{MC}$; bottom : anhydrous. Fine line : negative or zero shrinkage. On the total shrinkage mapping (bottom), the mapping by zinc chloro-iodide coloration is superimposed for comparison. 
B. Clair et al. : Mapping Shrinkages and Relation to Tension Wood in Discs

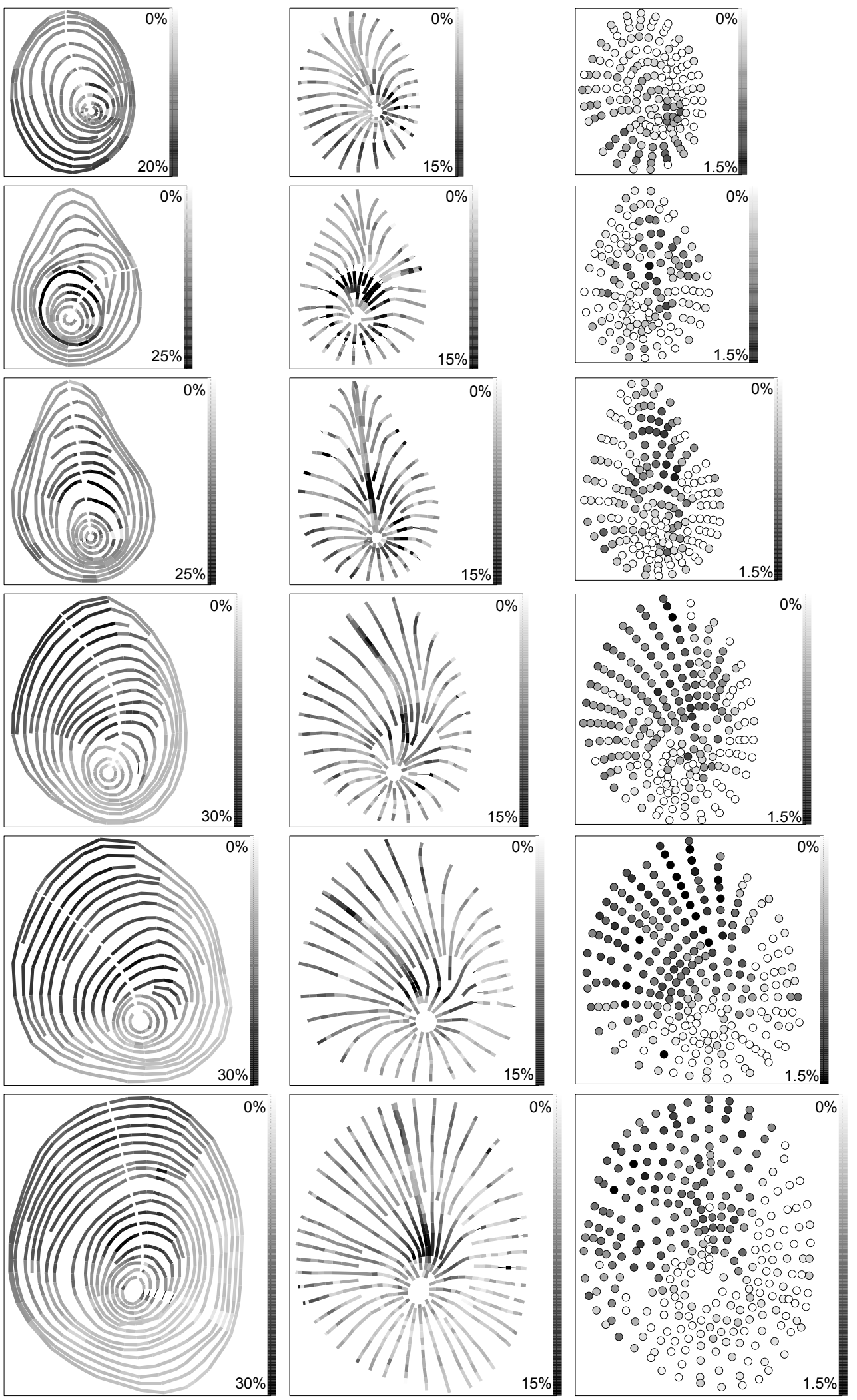

Fig. 6. Total shrinkage for 6 discs along the tree. Left : tangential shrinkage; middle : radial shrinkage; right : longitudinal shrinkage. Fine line or white spots : negative or zero shrinkage. 
B. Clair et al. : Mapping Shrinkages and Relation to Tension Wood in Discs
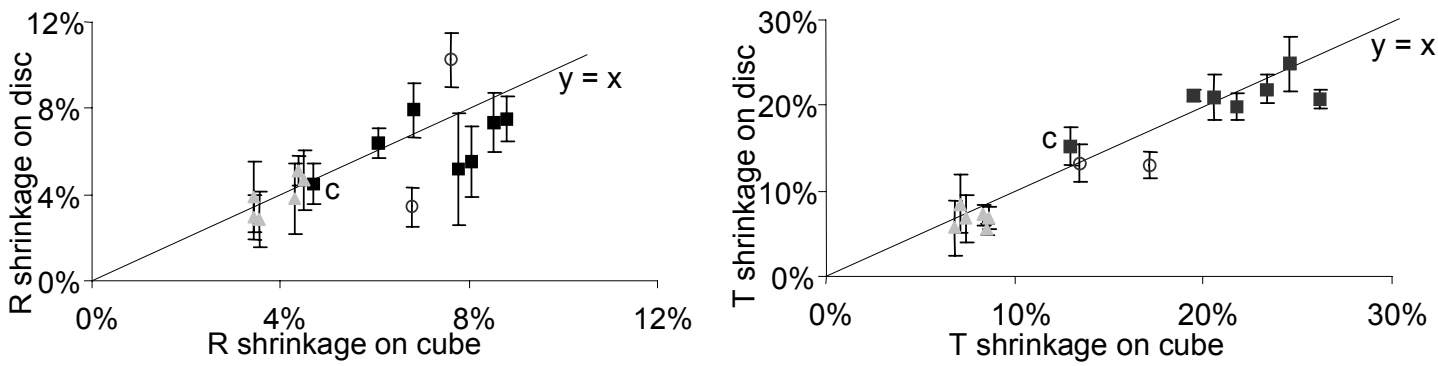

Fig. 7. Comparison between $R$ and $T$ shrinkage measured on discs and on cubes (correlation coefficient $R^{2}{ }_{R}=0.51, R^{2} T=$ 0.91). Back squares : tension wood; grey triangle : normal wood; empty spots : intermediate wood; the letter “ 